\title{
THE RESPIRATORY EFFECTS OF TONER EXPOSURE ACCORDING TO LONG-TERM OCCUPATIONAL TONER HANDLING HISTORY: A LONGITUDINAL ANALYSIS, 2004-2013
}

\author{
MASAYUKI HASEGAWA ${ }^{1}$, HIROKO KITAMURA ${ }^{1}$, KAZUNORI IKEGAMI ${ }^{1}$, MASASHI MASUDA ${ }^{2}$, \\ NORIAKI KAKIUCHI ${ }^{1}$, TETSUHIRO MATSUSHITA ${ }^{1}$, HIROAKI KUGA ${ }^{1,3}$, TETSURO UCHIYAMA ${ }^{1}$, \\ KAZUSHIRO KUROGI ${ }^{1}$, MITSUHITO MIZUNO ${ }^{1}$, AKIRA OGAMI ${ }^{1}$, and TOSHIAKI HIGASHI ${ }^{1}$
}

${ }^{1}$ University of Occupational and Environmental Health, Fukuoka, Japan

Institute of Industrial Ecological Sciences, Department of Work Systems and Health

${ }^{2}$ AEON Co., Ltd., Chiba, Japan

Human Resource Department

${ }^{3}$ Mazda Motor Corporation, Hiroshima, Japan

Health Promotion Center, Safety, Health and Disaster Prevention Promotion Department

\begin{abstract}
Objectives: This report shows the relationship between toner exposure and respiratory effects for individuals with a longterm occupational toner-handling history, from 2004 to 2013. Material and Methods: Authors studied 752 Japanese male workers in toner handling workshops. A total of 673 men who participated in an annual monitoring survey were analyzed in this study. The following monitoring was performed in the same season each year: personal exposure measurements, biological markers, respiratory function tests, a chest X-ray, chronic respiratory symptoms and incidences of respiratory diseases. To evaluate the toner exposure effect, the exposure categories suitable for each evaluation index were established. Results: For those with an occupational toner-handling history, the mean occupational toner-handling period was 14.36 years (standard deviation $=6.62$ ); one participant had 35 years of exposure, which was the longest and one participant had 1 year of exposure which was the shortest. There were no statistically significant differences in the rate of change of respiratory function tests. An ANOVA conducted on blood and urine test results showed that statistically significantly differences were observed for a few items but all the values were very low and within the standard range. Conclusions: Authors conducted a 10-year ongoing study, but no obvious negative influences on health were attributed to toner exposure. In a work environment where adequate administrative controls are in place, personal toner exposure levels may be expected to be low, with no adverse effects on human health. Int J Occup Med Environ Health 2018;31(6):809-822
\end{abstract}

Key words:

Respiratory disease, Printer, Toner dust, Longitudinal analyses, Respiratory effects, Occupational exposure

Funding: this study was supported by Canon Inc (project No. toner cohort_20040358 entitled "The relationship between toner-handling work and health effects," project managers: Akira Ogami and Toshiaki Higashi).

Received: October 11, 2017. Accepted: February 14, 2018.

Corresponding author: Masayuki Hasegawa, University of Occupational and Environmental Health, Institute of Industrial Ecological Sciences, Department of Work Systems and Health, Ins1-1, Iseigaoka, Yahata-nishi-ku, Kitakyushu, 807-8555, Fukuoka, Japan (e-mail: h_masayuki@med.uoeh-u.ac.jp). 


\section{INTRODUCTION}

With the advancement of information technology (IT), peripheral computer equipment such as copying machines and printers have become a commonplace at homes and at workplaces; the number of users and the rates of usage have also increased rapidly. Toner is the powdery printing medium used by copying machines and printers.

In 1994, an article in the "Lancet" reported a case of siderosilicosis in the case of a worker in the printing industry that was thought to be caused by toner exposure [1]. Thereafter, cases of granulomatous pneumonitis and bronchial asthma related to toner exposure in workers working at newspaper companies were reported [2-4]. In 1996, carbon black, the main component of toner, was classified as group 2B by the International Agency for Research on Cancer (IARC) [5]. Moreover, lung tumors related to artificial and massive inhalation exposure of diesel exhaust emission and others were identified in animal studies [6-8], and raised concerns about the carcinogenic risks related to the exposure to various types of dusts.

Although several studies had examined the effects of toner exposure on human health, the exposure history in the case reports were unclear, and no adequate evidence of carcinogenesis related to toner exposure in humans has been reported. Therefore, an epidemiological study among humans with known exposure status is required to clarify the effects of toner exposure on health.

Some studies have investigated toner exposure and its effects on health in Japanese toner and photocopier manufacturing companies using various methods and have reported no health effects of toner exposure [9-14]. However, some of these studies have had a cross-sectional study design whereas others have had other limitations such as a very small sample size. Particularly, the health effects of toner exposure for workers with a long-term history of toner-handling (i.e., > 10 years) have not been evaluated to date.
Thus, authors conducted a 10-year cohort survey (20042013) for 760 workers working at a toner manufacturer where toner exposure was considered the highest. The health effects of toner exposure were analyzed considering the workers' long-term engagement in toner work; i.e., including their history of toner-handling before 2004. The main aim of this study has been to clarify the effects of long-term toner exposure on respiratory health.

\section{MATERIAL AND METHODS}

\section{Subjects}

A total of 752 men working in 6 factories of a Japanese toner and photocopier manufacturing company were eligible to participate in the study; all participants were $<50$ years old in 2004.

The following inclusion criteria were employed to evaluate changes in respiratory health during the study period of 10 years: the subjects had to participate in the first (2004) and last surveys (2013) and participate $\geq 5$ times to avoid overestimating temporary changes in the calculations of the year-over-year percent changes in the respiratory function test. After excluding 78 subjects who did not participate in the survey in 2013 (fiscal years were used in this study) and 1 who participated $<5$ times, 673 subjects were included in the final analyses. The inclusion rate was $89.5 \%$ (673/752).

\section{Exposure categories}

The subjects' occupational history and current duties regarding toner-handling were investigated using annual self-reported questionnaires. To evaluate the effects of toner exposure on respiratory health, 3 exposure categories were established (Figure 1):

1. The panel data analysis according to annual toner exposure. Toner exposure in each year was assessed with the self-reported questionnaire, and a panel data analysis according to annual toner exposure was conducted. The subjects were classified as the toner-handling 

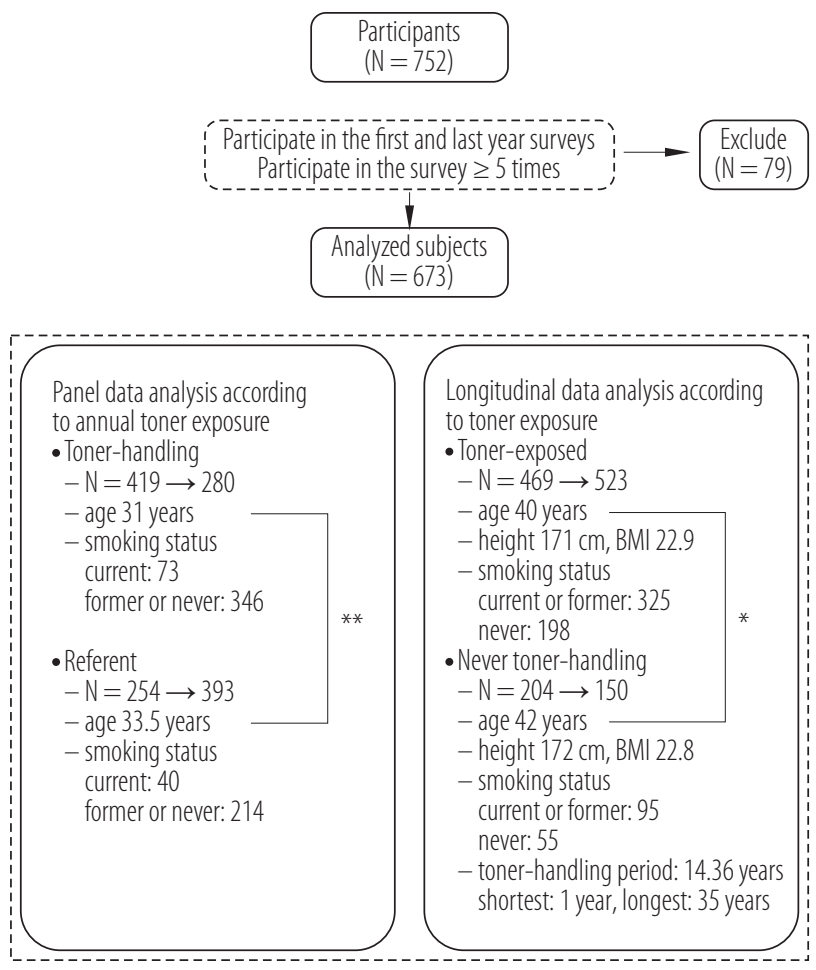

BMI - body mass index.

Panel data analysis according to annual toner exposure;

n: $2004 \rightarrow$ 2013, age: median in 2004, smoking status: number in 2004.

Longitudinal data analysis according to toner exposure;

$\mathrm{n}: 2004 \rightarrow$ 2013, age: median in 2013, height; median in 2013, BMI;

median in 2013, smoking status: number in 2013.

Toner-handling period: the mean occupational toner-handling period.

Analysis was performed between toner-handling and referent,

toner-exposed and never toner-handling, age, height,

BMI: Mann-Whitney U test, smoking status: $\mathrm{Chi}^{2}$ test.

Mann-Whitney U test * $\mathrm{p}<0.05 ;{ }^{* *} \mathrm{p}<0.01$.

Fig. 1. Profile of selection of subjects and characteristics

group and reference (not currently engaged in tonerhandling) group. And blood tests, reflecting the acute effects of toner exposure, were assessed using this category.

2. The longitudinal data analysis according to toner exposure. Workers who had been exposed to toner in the past or during the survey as "toner-exposed" and those who had never been exposed to toner as "never tonerhandling" were then defined. The longitudinal analysis was conducted to evaluate the chronic effects of toner exposure, which were evaluated using respiratory function tests, chest radiography, self-reported chronic symptoms, and self-reported incidence of new-onset respiratory diseases.

3. The long-term occupational toner-handling history. The subjects' long-term occupational toner-handling history was calculated by adding the time of occupational toner-handling during the survey period to that of occupational toner-handling in the past (before 2004), which was determined based on the questionnaire. The association between long-term occupational tonerhandling history and annual changes in the respiratory function test was evaluated.

\section{Measurements of personal toner exposure}

Annual personal toner exposure measurements were conducted for subjects who had been randomly selected from the total subjects of the toner-handling and reference groups at the 6 factories.

The exposure assessments were performed using the personal respirable dust sampler, model PS-47, type Roken (Shibata Scientific Technology Ltd, Saitama, Japan) with glass fiber filters and polytetrafluoroethylene (PTFE)-binding (type T60A20). The device had a filter with a diameter of $\varphi 25 \mathrm{~mm}$ and a flow rate of $2 \mathrm{~m} / \mathrm{s}$. The subjects wore the data recorder of the personal dust sampler on the left side of their waist and the detector around their necks. Respirable dust trapped in the filter was measured with an electric balance, and the measured quantity was divided by the total aspirated air volume to calculate the respirable dust concentration. To compare the exposure level with the threshold limit value (TLV) defined by the American Conference of Governmental Industrial Hygienists (ACGIH), which was based on the allowable exposure averaged over a normal 8-h workday or 40-h work week, the 8-h time-weighted average values (TWA 8h) were calculated. 
The subjects were also requested to describe their workplace, the details of their work, length of the breaks, using the monitoring record.

\section{Biomarkers of the respiratory system}

Serum and urine biomarkers as well as leukocyte counts were measured to evaluate the effects of toner exposure on the respiratory health of the study participants.

Leukocyte counts, C-reactive protein (CRP) (high-sensitive CRP was employed from 2008 onwards), interleukin-6 (IL-6), and interferon gamma (IFN- $\gamma$ ) were measured as representative inflammatory markers; sialylated carbohydrate antigen KL-6 (KL-6) and surfactant protein D (SP-D) were used as well-known markers of interstitial pneumonia; urinary 8-hydroxy-2'-deoxyguanosine (8-OHdG) was used as a marker of oxidative stress; and immunoglobulin $\mathrm{E}(\mathrm{IgE})$ was measured as a marker of allergies. Leukocyte counts, CRP, and 8-OHdG levels were determined annually whereas the other items were determined every other year (2004, 2006, 2008, 2011, and 2013).

Blood samples were obtained to measure leucocyte counts as well as CRP, IL-6, IFN- $\gamma$, KL-6, and SP-D levels. These tests were performed at the Special Reference Laboratory, Inc. (SRL Inc. Tokyo, Japan). Urinary 8-OHdG was measured at the OHG Institute Co. Ltd (Fukuoka, Japan). Serum CRP levels were measured using a turbidimetric immunoassay (TIA) from 2004 to 2006, a latex immunoagglutination assay (LA) in 2007, and a latex nephelometric immunoassay from 2008 onwards. Serum IL-6 levels were measured with a chemiluminescent enzyme immunoassay (CLEIA), serum KL-6 levels with an electro-chemiluminescence immunoassay (ECLIA), and serum IFN- $\gamma$ and SP-D levels with an enzyme immunoassay (EIA). Leukocyte counts were measured using an automated cell counter. Urinary 8-OHdG levels were measured using high-performance liquid chromatography (HPLC), and the corrected values were adjusted using urine creatinine concentrations. The limits of detection (LOD) of SRL Inc. were $0.1 \mathrm{mg} / \mathrm{dl}$ for CRP for the TIA, $0.01 \mathrm{mg} / \mathrm{dl}$ for CRP for the LA, $0.004 \mathrm{mg} / \mathrm{dl}$ for CRP for the latex nephelometric immunoassay, and $17.2 \mathrm{ng} / \mathrm{ml}$ for SP-D.

\section{Pulmonary function tests}

Pulmonary function tests were performed annually with a pneumotach-type spirometry measuring unit, such as the Microspiro HI-701 and Microspiro HI-801 (Chest Corporation, Tokyo, Japan), meeting the standards stipulated by the American Thoracic Society. Since habituation and skill level of the subjects affect the test results, the test was conducted 3 times and the best result was chosen. The forced vital capacity (FVC), forced expiratory volume in $1 \mathrm{~s}\left(\mathrm{FEV}_{1}\right)$, and forced expiratory volume percentile in $1 \mathrm{~s}\left(\mathrm{FEV}_{1} \%\right)$ were analyzed. The personal annual change was calculated from the measured values for FVC, $\mathrm{FEV}_{1}$, and $\mathrm{FEV}_{1} \%$ by determining the calibration curve from the measured values in each subject $>10$ years and considering its slope the annual change (1/year or \%/year). Since few measuring points might cause over/underestimation of changes, the data of 5 subjects of the toner-handling group whose respiratory function was determined $<4$ times were excluded from the analysis; thus, data from 518 subjects was included in the analysis.

\section{Chest radiography}

According to the internationally comparable standard method specified in the Pneumoconiosis Law [15], annual chest radiography examinations were conducted. The results were interpreted by 2 physicians, based on the international classification of pneumoconiosis.

\section{Incidence of chronic respiratory symptoms and new-onset respiratory diseases}

The self-reported subjects' medical histories and present respiratory illnesses and symptoms were assessed using the Japanese version of the American Thoracic Society Division of Lung Disease adult question- 
naire (ATS-DLD-78) [16] once yearly. Three chronic respiratory symptoms were evaluated: persistent cough (a cough that is observed $>4$ times daily and that persists almost daily for $>3$ months), persistent phlegm (phlegm that is observed $>4$ times daily and that persists almost daily for $>3$ months), and chronic breathlessness (breathing that becomes difficult when walking on a flat road in a hurry or climbing a gentle slope). The morbidity rates of the respiratory diseases were calculated using the following equation and conditions:

$$
\begin{gathered}
\begin{array}{c}
\text { morbidity rate } \\
\text { of respiratory } \\
\text { disease }
\end{array} \\
\begin{array}{c}
\text { of all subjects in the observation } \\
\text { group (toner-handling } \\
\text { or reference) }
\end{array}
\end{gathered}
$$

Subjects who had a respiratory disease before the study period were excluded from the study. Subjects who had a respiratory disease during the observation period were excluded from the subsequent analysis. If a subject had a respiratory disease at any point of a particular year, the person-years were calculated as 0.5 person-years.

\section{Data analyses}

The biomarker levels were analyzed using the panel data analysis according to annual personal toner exposure. Each biomarker was transformed logarithmically, considering the effects of the distribution on the statistical analysis, and analyzed as a dependent variable using two-way analysis of variance (ANOVA) with a post hoc Tukey test. The time-point exposure and smoking status were used as independent variables. As KL-6 and SP-D levels were considered indices reflecting chronic changes based on previous studies, an analysis using the cumulative exposure was also conducted [17-19]. As the biomarkers used in this study are thought to be affected little by aging, they were not included in the explanatory variables.
The changes in pulmonary function test results were caclulated in terms of the period of 10 years. The relationships between the annual changes and the longitudinal data methods according to toner exposure were analyzed using the Mann-Whitney $U$ test. A multiple regression analysis using the respiratory function test parameters (FVC, $\mathrm{FEV}_{1}$, and $\mathrm{FEV}_{1} \%$ ) as the objective variables and age, height, the long-term occupational toner-handling history, and smoking history (indices known to affect occupational respiratory function) as the explanatory variables, was also conducted.

For the chest radiography results, the relationship between the incidence of pneumoconiosis in each year and the cumulative exposure category using the $\mathrm{Chi}^{2}$ test were examined. The $\mathrm{Chi}^{2}$ test was also used for analyzing the relationships between the prevalence of the chronic respiratory symptoms/new-onset respiratory diseases and the longitudinal data methods according to toner exposure.

All statistical analyses were conducted using SPSS 22.0J (IBM SPSS Inc., former SPSS Inc.). Probability values of 0.05 were considered to indicate statistical significance.

\section{Ethical approval}

This study was reviewed and approved by the Human Ethics Committee for Epidemiological Research at the University of Occupational and Environmental Health, Japan.

\section{RESULTS}

\section{Personal toner exposure}

The 8-h weighted mean concentration of personal dust exposure was calculated and compared to the acceptable concentration of $3 \mathrm{mg} / \mathrm{m}^{3}$ for an "unclassifiable non-water soluble or insoluble substance," as defined by the ACGIH. The results by year and factory from 2004 to 2013 are shown in the Figure 2. Most 8-h weighted mean concentrations were very low and $<1 / 10$ of the acceptable concentration $\left(0.3 \mathrm{mg} / \mathrm{m}^{3}\right)$. 


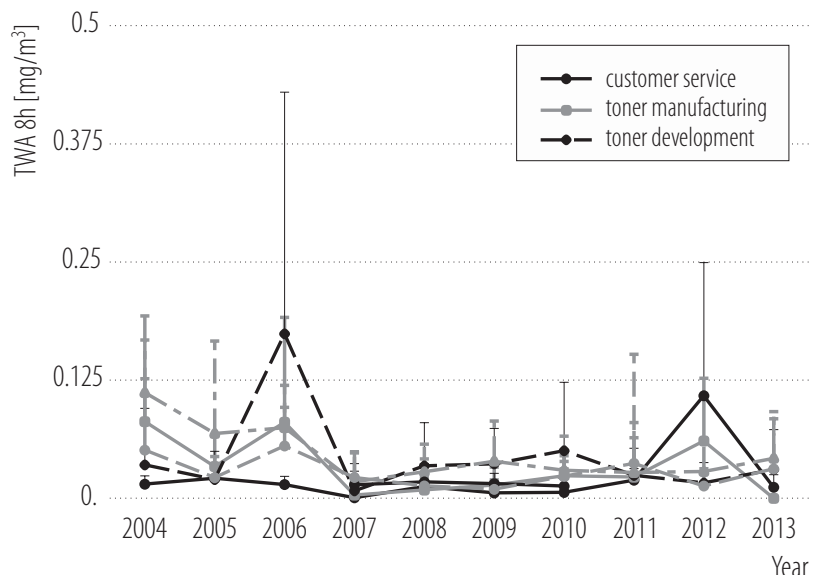

The acceptable concentration of $3 \mathrm{mg} / \mathrm{m}^{3}$ of the "unclassifiable non-water soluble or insoluble substance" presented by American Conference of Governmental Industrial Hygienists (ACGIH) [28].

Fig. 2. Time-weighted average in 8h (TWA 8h) of personal exposure measurement

\section{Subject characteristics}

The panel data analysis was conducted to assess the changes according to toner exposure in each year (Figure 1). Whereas in 2004, 419 and 254 subjects were in the toner-handling and reference groups, respectively, 280 and 292 subjects were in the 2 groups, respectively, in 2013, indicating that the number of toner-handling workers tended to decrease over time. In 2004, the median age of the subjects was significantly lower in the toner-handling than in the reference group, with a mean difference of 2.5 years. No significant differences were found in the smoking status between the 2 groups.

The Figure 1 also depicts the annual changes in the longitudinal data analysis according to toner exposure and participant statistics including age, height, smoking status and history of toner exposure. In 2004, 469 and 204 subjects were in the toner-exposed and never toner-handling groups, respectively, whereas they were 523 and 150 subjects, respectively, in 2013. Among those with no toner exposure at baseline, 54 subjects became engaged in toner-handling work during the study period. In 2013, the median age was significantly lower in the toner-exposed group than in the never toner-handling group, with a mean difference of 2 years. No significant differences were observed for smoking status, height, and body mass index (BMI) between the 2 groups. The evaluation of the long-term occupational tonerhandling history showed that the mean occupational toner-handling period was 14.36 years (standard deviation $[\mathrm{SD}]=6.62$ years); the longest and shortest periods were 35 years and 1 year, respectively.

\section{Biomarker analyses}

The Table 1 shows the effects of toner exposure on biomarker levels using panel data analysis according to annual toner exposure. Although significant differences were found in biomarker concentrations associated with toner exposure for some biomarkers, all biomarker concentrations were lower in the toner-handling group than in the reference group.

When analyzing the interaction between toner exposure and smoking, a significantly higher SP-D concentration (reference, $<110 \mathrm{ng} / \mathrm{ml}$ ) was found among current smokers in the toner-handling group when compared to the reference group $(1.59 \mathrm{ng} / \mathrm{ml}$ vs. $1.52 \mathrm{ng} / \mathrm{ml}$, respectively) in 2011. In 2013, the SP-D concentration showed a significant difference between the toner-handling group and the reference group in the two-way ANOVA but not in the multiple comparison. Among those who reported past or never smoking, a significantly higher IgE concentration (reference, $\leq 173 \mathrm{IU} / \mathrm{ml}$ ) was found in the toner-handling group when compared to the reference group in both 2011 and 2013 (2011: 99.3 IU/ml vs. 74.4 IU/ml, respectively; 2013: $110.7 \mathrm{IU} / \mathrm{ml}$ vs. $72.8 \mathrm{IU} / \mathrm{ml}$, respectively).

As KL-6 and SP-D levels are thought to reflect chronic changes of respiratory health, a longitudinal data analysis was conducted according to toner exposure. In both 2008 and 2013, the KL-6 levels (reference, < $500 \mathrm{U} / \mathrm{ml}$ ) among those who reported never smoking were significantly higher in the toner-exposed group when compared to the never toner-handling group (2008: $196.3 \mathrm{U} / \mathrm{ml}$ vs. $175.8 \mathrm{U} / \mathrm{ml}$, respectively; 2013: $223.9 \mathrm{U} / \mathrm{ml}$ vs. $201.4 \mathrm{U} / \mathrm{ml}$, respectively). 


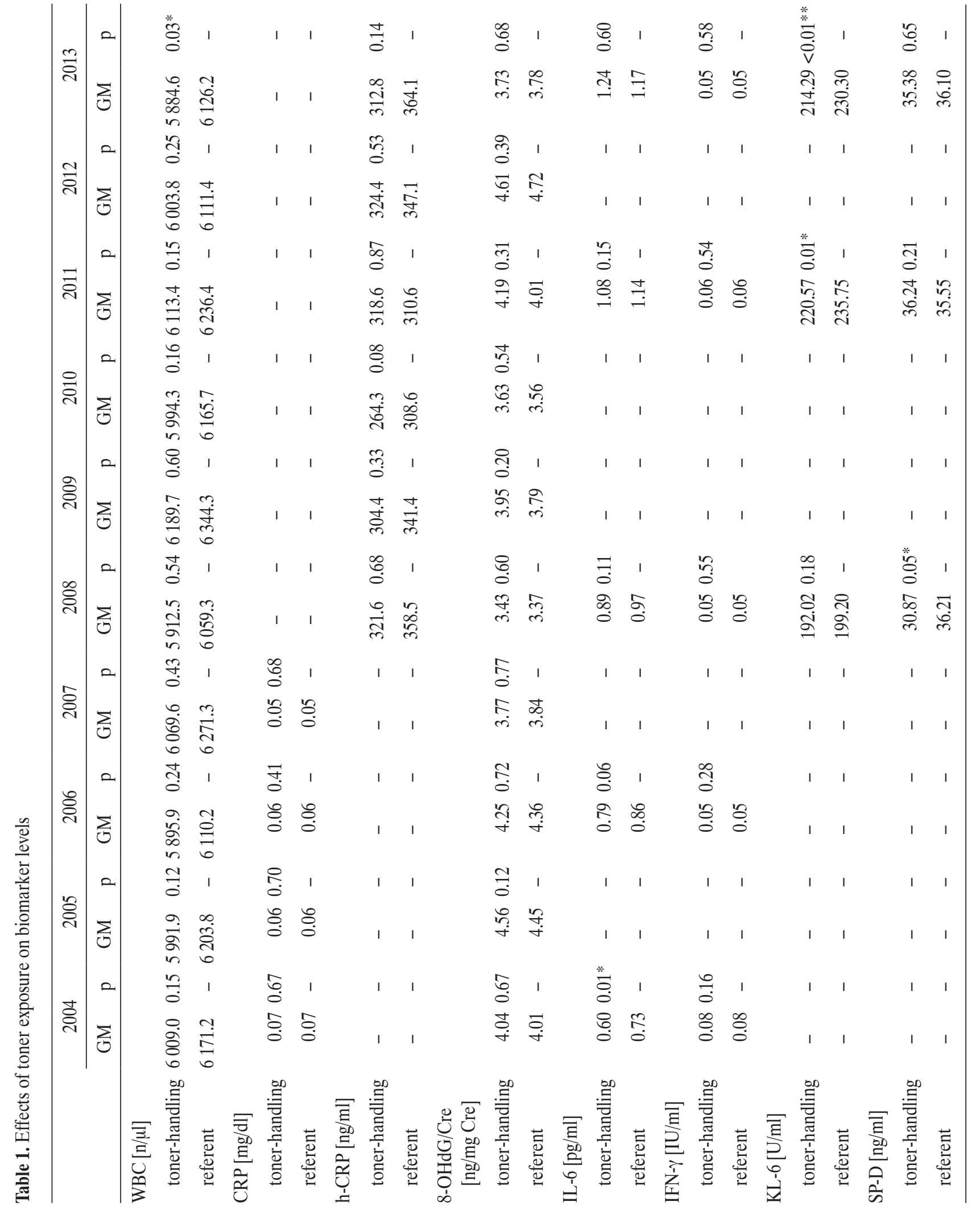




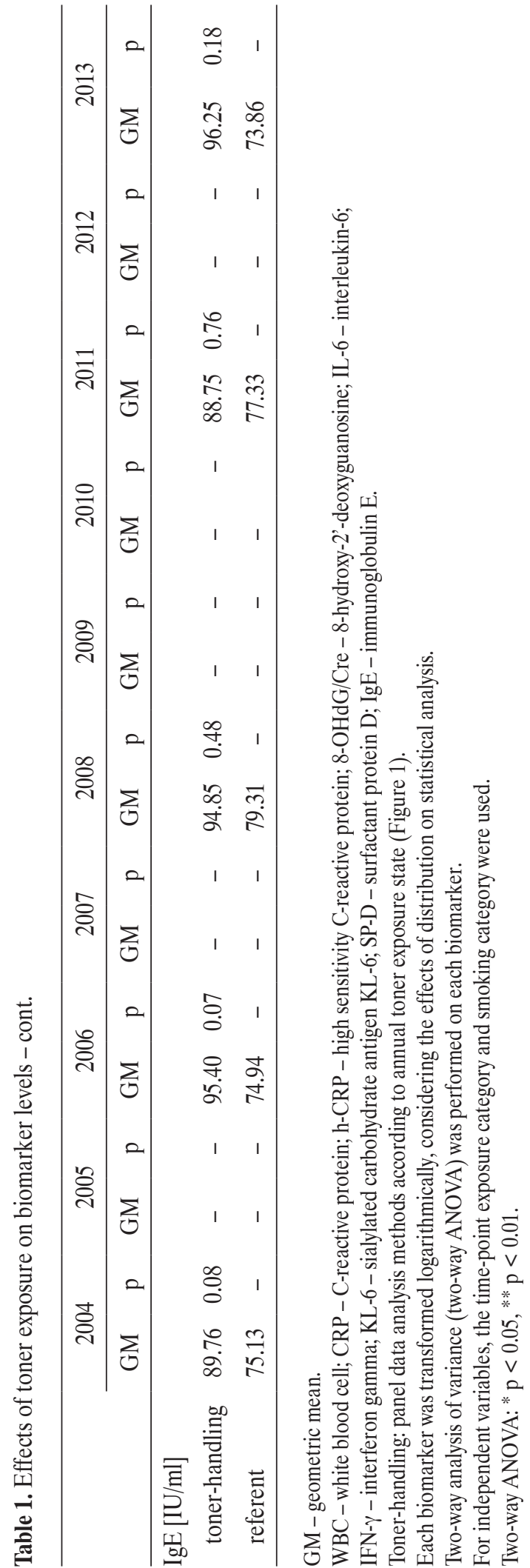

Although statistically significant differences were detected for a few biomarkers, all values were very low and within the reference ranges.

\section{Pulmonary function tests}

The annual changes in $\mathrm{FVC}, \mathrm{FEV}_{1}$, and $\mathrm{FEV}_{1} \%$ were analyzed using the longitudinal data analysis according to toner exposure in 518 subjects in the toner-exposed group and 150 subjects in the never toner-handling group and found no significant differences for any of the parameters (Table 2). As the respiratory function test is affected by smoking, the subjects' smoking status was also taken into consideration. When the subjects were analyzed by smoking status (current or former smoker vs. never-smoker), no significant differences were observed.

Since the length of exposure is important for respiratory function, the association between a long-term occupational toner-handling history and changes in respiratory function was also evaluated (Figure 3). No correlations were found for any of the variables, including the longterm occupational toner-handling history. In the multiple regression analysis, no variables were found to affect annual changes in respiratory function.

\section{Chest radiography}

The results of the chest radiography examinations were compared using the longitudinal data analysis according to toner exposure. The incidences of pneumoconiosis findings, fibrosis of the lung and the tumor shadow were compared in each year and detected no statistically significant differences between toner-exposed and never toner-handling.

\section{Incidence of chronic respiratory symptoms} and new-onset respiratory diseases

As chronic respiratory symptoms and the new-onset respiratory diseases are thought to be affected by occupational toner-handling, a longitudinal data analysis was conducted according to toner exposure. 
Table 2. Comparison of the annual change of respiratory function indices

\begin{tabular}{|c|c|c|c|c|c|}
\hline \multirow{2}{*}{ Variables in groups } & \multicolumn{2}{|c|}{$\begin{array}{l}\text { Toner-exposed } \\
\quad(\mathrm{N}=518)\end{array}$} & \multicolumn{2}{|c|}{$\begin{array}{l}\text { Never toner-handling } \\
\quad(\mathrm{N}=150)\end{array}$} & \multirow{2}{*}{$\mathrm{p}$} \\
\hline & $\mathrm{Me}$ & median rank & $\mathrm{Me}$ & median rank & \\
\hline \multicolumn{6}{|l|}{ Current or former smokers } \\
\hline FVC [1/year] & -0.008 & 201.25 & -0.008 & 195.84 & 0.69 \\
\hline $\mathrm{FEV}_{1}[1 /$ year $]$ & -0.021 & 200.44 & -0.023 & 196.36 & 0.77 \\
\hline $\mathrm{FEV}_{1} \%[\% /$ year $]$ & -0.236 & 200.23 & -0.235 & 199.22 & 0.94 \\
\hline \multicolumn{6}{|l|}{ Never smokers } \\
\hline FVC [1/year] & -0.007 & 135.98 & -0.011 & 133.74 & 0.85 \\
\hline $\mathrm{FEV}_{1}[1 /$ year $]$ & -0.019 & 136.42 & -0.020 & 132.16 & 0.71 \\
\hline $\mathrm{FEV}_{1} \%[\% /$ year $]$ & -0.260 & 136.29 & -0.253 & 132.6 & 0.75 \\
\hline \multicolumn{6}{|l|}{ Total } \\
\hline FVC [1/year] & -0.007 & 336.86 & -0.011 & 328.56 & 0.64 \\
\hline $\mathrm{FEV}_{1}[1 /$ year $]$ & -0.020 & 336.87 & -0.022 & 326.31 & 0.56 \\
\hline $\mathrm{FEV}_{1} \%[\% /$ year $]$ & -0.245 & 336.13 & -0.253 & 331.1 & 0.78 \\
\hline
\end{tabular}

FVC - forced vital capacity; $\mathrm{FEV}_{1}$ - forced expiratory volume in $1 \mathrm{~s} ; \mathrm{FEV}_{1} \%$ - forced expiratory volume percentile in $1 \mathrm{~s}$.

${ }^{a}$ Toner-exposed: longitudinal data analysis according to toner exposure (Figure 1).

Current or former smoker: toner-exposed $\mathrm{N}=306$, never toner-handling $\mathrm{N}=92$.

Never smoker: toner-exposed $\mathrm{N}=212$, never toner-handling $\mathrm{N}=58$.

The annual change was calculated by determining the calibration curve from the measured values in each subject in 10 years, and its slope was considered the annual change (1/year or \%/year).

Mann-Whitney U test was performed between toner-exposed group and never toner-handling group.

Analyzed by classifying into a group of current or former smoker and a group of never-smoker.

Subjects who participated in the survey in 2004 and 2013 were only included; therefore, the information of the subjects, who refused to participate and of those who were lost to follow-up due to death, was analyzed. Whereas 11 subjects refused to participate, 19 were lost to follow-up due to retirement. Among those who refused to participate, none refused due to health concerns. A total of 5 deaths were observed during the study period ( 3 and 2 in the tonerexposed and never toner-handling groups, respectively). Among the deaths in the toner-exposed group, 2 were attributable to gastrointestinal tumors and 1 to non-healthrelated causes. These deaths likely did not occur due to toner exposure. Among the deaths in the never toner-handling group, 1 was attributable to a blood disease and 1 to cardiac disease.
The incidence of new-onset diseases during the study period is shown in the Table 3. Pneumoconiosis, granulomatous interstitial pneumonia, lung cancer, and bronchial asthma were established as the target diseases; however, no cases of pneumoconiosis or granulomatous interstitial pneumonia were observed. There was one case of lung cancer during the study period in the toner-exposed group in 2013 and none in the never toner-handling group. The morbidity rate of lung cancer in the toner-exposed group was $0.22 / 1000$ person-years. The morbidity rate of bronchial asthma was slightly higher in the toner-exposed group than in the never toner-handling group, with a relative risk of 1.16 (95\% confidence interval (CI): 0.38-3.5); this finding was not statistically significant. When compared to the never toner-handling group, the proportion 

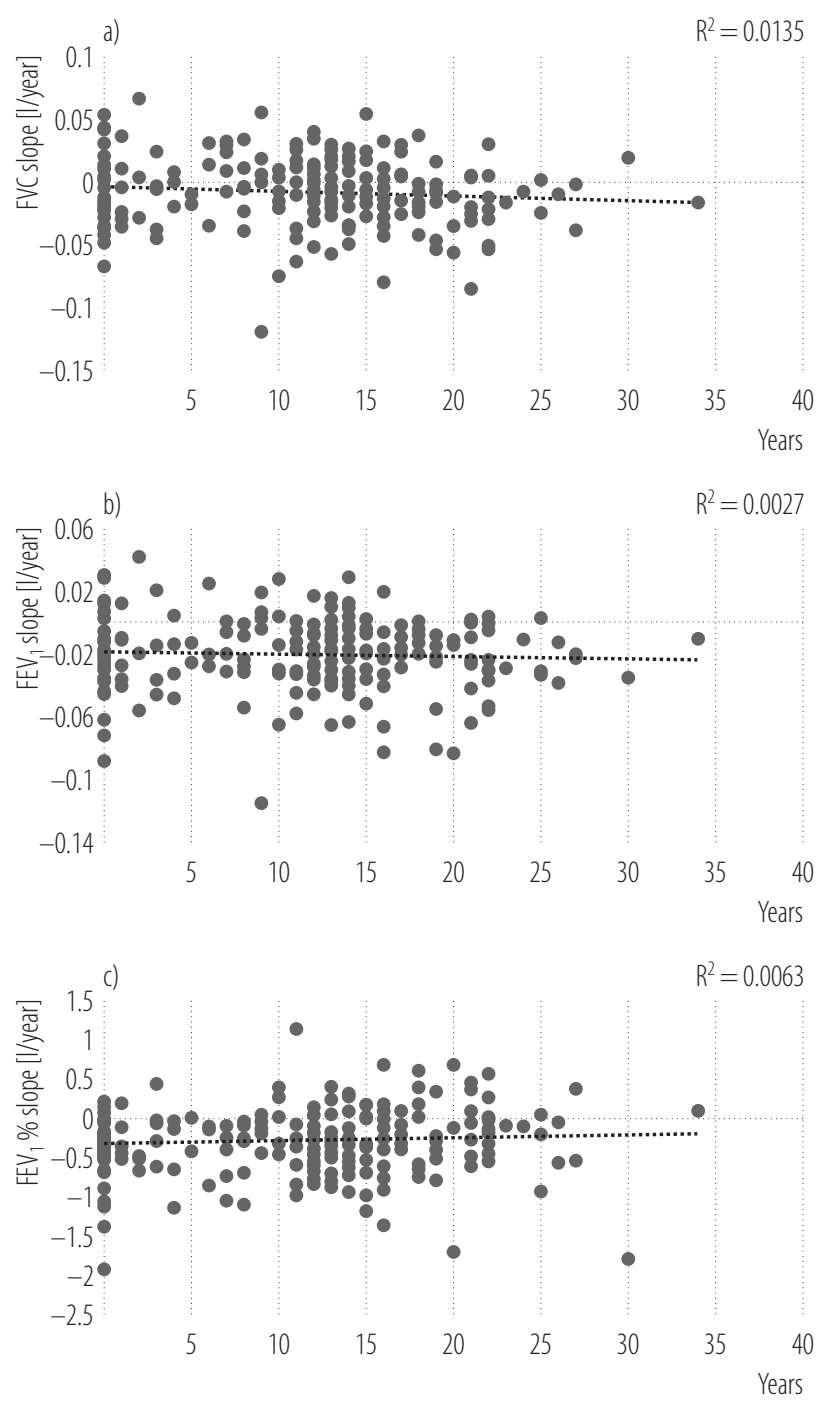

$\mathrm{R}^{2}$ - the coefficient of determination.

The personal annual change was calculated by determining the calibration curve from the measured values in each subject in 10 years, and its slope was considered the annual change (1/year or \%/year).

Fig. 3. The relationship between the personal annual change of respiratory function indices and years of toner-handling in never smokers: a) forced vital capacity (FVC), b) forced expiratory volume in $1 \mathrm{~s}\left(\mathrm{FEV}_{1}\right)$ and forced expiratory volume percentile in $1 \mathrm{~s}\left(\mathrm{FEV}_{1} \%\right)$

of subjects reporting "persistent phlegm" in 2006 was significantly high in the toner-exposed group. No significant differences were observed for the other chronic respiratory symptoms.

\section{DISCUSSION}

\section{Personal toner exposure}

A very low personal dust exposure level was detected in this study; thus, the exposure level to toner particles is also considered very low. The highest value measured during the study period was $1.989 \mathrm{mg} / \mathrm{m}^{3}$ in 2012; even this value was below the acceptable concentration of $3 \mathrm{mg} / \mathrm{m}^{3}$ specified by the ACGIH. Therefore, the work environment of the workplaces analyzed in this study may be considered appropriately controlled. In this study, the measurement started when the device was first worn in the office before the start of toner handling. Therefore, the start value should have been the same as the value measured in the office. However, a very high value was shown immediately after the start of the measurements when the highest value was recorded in 2012. It is highly probable that this value was caused by mechanical malfunction. Therefore, it is less significant to use the exposure level as a variable in the analyses and more reasonable to compare the findings between the exposure groups.

\section{Biomarker analyses}

The significantly higher SP-D and $\operatorname{IgE}$ concentrations were found in the time-point exposure analysis in the toner-handling when compared to the reference group. For cumulative exposure, KL-6 concentration was significantly higher in the toner-exposed group when compared to the never toner-handling group. However, the difference was very small, and the values were within the reference range. As the toner-handling group did not show consistently higher values than the reference group in any biomarker throughout the study period, there seem to have been no health effects related to toner exposure. Previous studies similarly reported no effect of toner exposure on biomarker levels, which was consistent with our results $[9,10]$.

\section{Pulmonary function tests}

No significant annual changes were found in the respiratory function test results in the cumulative exposure 
Table 3. Comparison of the morbidity rate

\begin{tabular}{|c|c|c|c|}
\hline Disease in group & $\begin{array}{l}\text { Disease onset } \\
{[\mathrm{n}]}\end{array}$ & Person-year & $\begin{array}{c}\text { Morbidity rate } \\
{[1000 \text { person-year }]}\end{array}$ \\
\hline \multicolumn{4}{|l|}{ Pneumoconiosis } \\
\hline toner-exposed ${ }^{\mathrm{a}}$ & 0 & 4620.0 & 0 \\
\hline never toner-handling & 0 & 1437.0 & 0 \\
\hline \multicolumn{4}{|l|}{ Granulomatous interstitial pneumonia } \\
\hline toner-exposed ${ }^{\mathrm{a}}$ & 0 & 4620.0 & 0 \\
\hline never toner-handling & 0 & 1437.0 & 0 \\
\hline \multicolumn{4}{|l|}{ Lung cancer } \\
\hline toner-exposed ${ }^{\text {a }}$ & 1 & 4619.5 & $0.22^{\mathrm{b}}$ \\
\hline never toner-handling & 0 & 1437.0 & 0 \\
\hline \multicolumn{4}{|l|}{ Bronchial asthma $^{c}$} \\
\hline toner-exposed $\mathrm{d}^{\mathrm{a}}$ & 15 & 4123.5 & 3.64 \\
\hline never toner-handling & 4 & 1276.0 & 3.13 \\
\hline
\end{tabular}

a Toner-exposed: longitudinal data analysis according to toner exposure (Figure 1).

${ }^{\mathrm{b}}$ The morbidity rate of lung cancer in males aged 20-59 years was 0.22, disclosed by National Cancer Center Japan in 2010 [23].

${ }^{\mathrm{c}}$ The relative risk of bronchial asthma was 1.16 (95\% CI: 0.38-3.5).

analysis. Several cross-sectional [11,12] and longitudinal studies $[13,14]$ have been published regarding the effects of toner exposure on respiratory function and have been reported that toner exposure affects respiratory function seems extremely low.

Respiratory function decreases with aging. The Japanese Respiratory Society established the prediction equations, $\mathrm{FVC}=-0.024 \mathrm{l} /$ year and $\mathrm{FEV}_{1}=0.028 \mathrm{l} /$ year, regarding the indices of respiratory function for men [20]. Since no values in our analyses exceeded these indices, toner exposure did not appear to affect respiratory function more than normal changes related to aging.

The study period of 10 years might have been insufficient to detect decreases in respiratory function. Therefore, the relationship between the long-term occupational toner-handling history and annual changes in respiratory function was analyzed. The longest reported history of occupational tonerhandling was 35 years in our study, which should be sufficient to evaluate the effects of toner exposure on respiratory function. No significant correlations were found between annual changes in respiratory function parameters and the length of exposure. This result demonstrates that, at least in a well-controlled work environment, respiratory function is not affected even when the exposure period increases.

\section{Chest radiography}

No significant differences were found among the incidence of pneumoconiosis findings, fibrosis of the lung and the tumor shadow, and the cumulative exposure category. A correlation between pneumoconiosis and the accumulation of dust exposure has been reported using chest radiography [21,22]; however, a marked organic change is not thought to occur due to long-term toner exposure.

\section{Incidence of chronic respiratory symptoms and new-onset respiratory diseases}

When assessing the incidence of chronic respiratory symptoms by cumulative toner exposure, a significant difference was observed for "persistent phlegm" in 2006. However, no significant differences were observed in the other years; 
moreover, only minor changes in the proportion of subjects self-reporting chronic respiratory symptoms were detected during the study period. Therefore, the finding of 2006 is likely not an effect of toner exposure. No significant differences were found between toner-exposed group and never toner-handling group for the other items.

One case of lung cancer was observed in the toner-exposed group. However, the morbidity rate was similar to or lower than the morbidity rate of lung cancer of 1.18 in Japanese men of all ages [23] and the morbidity rate of 0.22 in men aged 20-59 years old, published by the National Cancer Center Japan in 2010. The morbidity rate of bronchial asthma was higher in the toner-exposed group compared to never toner-handling group; however, the relative risk of 1.16 was not statistically significant.

In summary, no evidence was found to indicate that toner exposure might increase the incidence of respiratory diseases in our comprehensive analyses.

\section{Limitations and future research}

This study has several limitations. Firstly, no health effects attributable to toner exposure were observed; however, detailed dose-response relationships were not carried out. Therefore, a future study should perform such doseresponse relationships. Secondly, most 8-h weighted mean concentrations of toner exposure were low. As previous studies reported that toner only caused lung cancer in cases of overload exposure in a rat model [24,25], it was likely that toner exposure did not cause adverse health effects in an appropriate work environment. Thirdly, our assessments of the subjects' long-term occupational toner-handling history might have been inaccurate due to possible recall bias related to the subjects' toner handling history before 2004. Last, the health effects of nano particles released by a copying machine were not analyzed, but they had been noticed in recent years [26,27]. Future epidemiological studies of the health effects of such nano particles for persons who use printers should be conducted.

\section{CONCLUSIONS}

The 10-year longitudinal study was conducted for 673 subjects to assess the effects of toner exposure on respiratory health, using blood and urinary tests, respiratory function tests, chest radiography, as well as self-reported incidences of chronic respiratory symptoms and new-onset respiratory diseases. These items were compared and examined using exposure categories that were suitable for each evaluation index. No effects of toner exposure on the respiratory health of the subjects were found in this study. Based on our findings, toner exposure likely does not affect respiratory health in the workplace when the work environment is appropriately controlled.

\section{ACKNOWLEDGMENTS}

We would like to thank the Public Health Research Foundation, the Science Center of Industrial Hygiene, SRL Inc., OHG Institute Co., Ltd., Bio communication Inc., and Soft Wave Pro Co., Ltd. for their assistance and cooperation with laboratory and data analysis work.

\section{REFERENCES}

1. Gallardo M, Romero P, Sanchez-Quevedo MC, LopezCaballero JJ. Siderosilicosis due to photocopier toner dust. Lancet. 1994;344(8919):412-3, https://doi.org/10.1016/S0140 -6736(94)91441-9.

2. Armbruster C, Dekan G, Hovorka A. Granulomatous pneumonitis and mediastinal lymphadenopathy due to photocopier toner dust. Lancet. 1996;348(9028):690, https://doi. org/10.1016/S0140-6736(05)65119-7.

3. Wieriks J. Photocopier toner dust and lung disease. Lancet. 1996;348(9040):1518-9, https://doi.org/10.1016/S0140-67 36(05)65937-5.

4. Wittczak T, Walusiak J, Ruta U, Pałczyński C. Occupational asthma and allergic rhinitis due to xerographic toner. Allergy. 2003;58(9):957, https://doi.org/10.1034/j.1398-9995.2003. 00241.x.

5. IARC Working Group on the Evaluation of Carcinogenic Risk to Humans. Printing processes and printing inks, carbon 
black and some nitro compounds. In: IARC monographs volume on the evaluation of carcinogenic risks to humans. Lyon: International Agency for Research on Cancer; 1996.

6. Gallagher J, Heinrich U, George M, Hendee L, Phillips DH, Lewtas J. Formation of DNA adducts in rat lung following chronic inhalation of diesel emissions, carbon black and titanium dioxide particles. Carcinogenesis. 1994;15(7):1291-9, https://doi.org/10.1093/carcin/15.7.1291.

7. Nikula KJ, Snipes MB, Barr EB, Griffith WC, Henderson RF, Mauderly JL. Comparative pulmonary toxicities and carcinogenicities of chronically inhaled diesel exhaust and carbon black in F344 rats. Fundam Appl Toxicol. 1995;25(1):80-94, https://doi.org/10.1006/faat.1995.1042.

8. Heinrich U, Fuhst R, Rittinghausen S, Creutzenberg O, Bellmann B, Koch W, et al. Chronic inhalation exposure of Wistar rats and two different strains of mice to diesel engine exhaust, carbon black, and titanium dioxide. Inhal Toxicol. 1995;7(4):533-56, https://doi.org/10.3109/08958379 509015211.

9. Murase T, Kitamura H, Kochi T, Terunuma N, Kurosaki S, Hata K, et al. Distributions and ranges of values of blood and urinary biomarker of inflammation and oxidative stress in the workers engaged in office machine manufactures: Evaluation of reference values. Clin Chem Lab Med. 2013;51(2):421-8, https://doi.org/10.1515/cclm-2012-0330.

10. Kitamura H, Terunuma N, Kurosaki S, Hata K, Masuda M, Kochi T, et al. A cohort study of toner-handling workers on inflammatory, allergic, and oxidative stress markers: Crosssectional and longitudinal analyses from 2003 to 2008. Hum Exp Toxicol. 2015;34(4):337-44, https://doi.org/10. 1177/0960327113512339.

11. Nakadate T, Yamano Y, Adachi C, Kikuchi Y, Nishiwaki Y, Nohara M, et al. A cross sectional study of the respiratory health of workers handling printing toner dust. Occup Environ Med. 2006;63(4):244-9, https://doi.org/10.1136/ oem.2005.020644.

12. Kitamura H, Terunuma N, Kurosaki S, Hata K, Ide R, Kuga $\mathrm{H}$, et al. Cross-sectional study on respiratory effect of toner-exposed work in manufacturing plants, Japan: Pulmonary function, blood cells, and biochemical markers. Hum Exp Toxicol. 2009;28(6-7):331-8, https://doi.org/ 10.1177/0960327109105152.

13. Yanagi N, Kitamura H, Mizuno M, Hata K, Uchiyama T, Kuga H, et al. A 4-year follow-up cohort study of the respiratory functions in toner-handling workers. Saf Health Work. 2014;5(4):222-6, https://doi.org/10.1016/j.shaw.2014.07.001.

14. Ikegami K, Hasegawa M, Ando H, Hata K, Kitamura H, Ogami A, et al. A cohort study of the acute and chronic respiratory effects of toner exposure among handlers: A longitudinal analyses from 2004 to 2013. Ind Health. 2016;54(5):44859, https://doi.org/10.2486/indhealth.2015-0202.

15. Safety and Health Association. [Standard X-ray films for the diagnosis of pneumoconiosis]. Tokyo: Safety and Health Association; 1982. Japanese.

16. Ferris BG. Epidemiology standardization project. Am Rev Respir Dis. 1978;118(6): 1-120.

17. Kohno N, Kyoizumi S, Awaya Y, Fukuhara H, Yamakido M, Akiyama M. New serum indicator of interstitial pneumonitis activity. Sialylated carbohydrate antigen KL-6. Chest. 1989;96(1):68-73, https://doi.org/10.1378/chest.96.1.68. 18. Kuroki Y, Takahashi H, Chiba H, Akino T. Surfactant proteins A and D: Disease markers. Biochim Biophys Acta. 1998;1408(2-3):334-45, https://doi.org/10.1016/S09254439(98)00079-9.

19. Cummings KJ, Virji MA, Park JY, Stanton ML, Edwards NT, Trapnell BC, et al. Respirable indium exposures, plasma indium, and respiratory health among indium-tin oxide (ITO) workers. Am J Ind Med. 2016;59(7):522-31, https://doi.org/ 10.1002/ajim.22585.

20. The Japanese Respiratory Society Clinical Pulmonary Functions Committee. [The standard value of spirogram and arterial blood gas partial pressure in Japanese]. J Japan Resp Soc. 2001;39:1-17. Japanese.

21. Gardiner K, Trethowan NW, Harrington JM, Rossiter CE, Calvert IA. Respiratory health effects of carbon black: A survey of European carbon black workers. Br J Ind 
Med. 1993;50(12):1082-96, https://doi.org/10.1136/oem.50. 12.1082

22. Van Tongeren MJ, Gardiner K, Rossiter CE, Beach J, Harber P, Harrington MJ. Longitudinal analyses of chest radiographs from the European Carbon Black Respiratory Morbidity Study. Eur Respir J. 2002;20(2):417-25, https://doi.org /10.1183/09031936.02.00224502.

23. [Cancer Information Service] [Internet]. Tokyo: National Cancer Center Japan, Center for Cancer Control and Information Services; c2014-2018 [cited 2016 Jan 14]. [Cancer_incidence_2010]. Available from: https:/ganjoho.jp/reg_stat/ statistics/dl/index.html. Japanese.

24. Tomonaga T, Izumi H, Yoshiura Y, Myojo T, Oyabu T, Lee BW, et al. Assessment of pulmonary toxicity induced by inhaled toner with external additives. Biomed Res Int.2017;2017:4245309, https://doi.org/10.1155/2017/4245309.

25. Morimoto Y, Kim H, Oyabu T, Hirohashi M, Nagatomo H, Ogami A, et al. Negative effect of long-term inhalation of toner on formation of 8-hydroxydeoxyguanosine in DNA in the lungs of rats in vivo. Inhal Toxicol. 2005;17(13):749-53, https://doi.org/10.1080/08958370500224771.

26. Pirela S, Molina R, Watson C, Cohen JM, Bello D, Demokritou P, et al. Effects of copy center particles on the lungs: A toxicological characterization using a $\mathrm{Balb} / \mathrm{c}$ mouse model. Inhal Toxicol. 2013;25(9):498-508, https://doi.org/10. 3109/08958378.2013.806614.

27. Khatri M, Bello D, Pal AK, Cohen JM, Woskie S, Gassert T, et al. Evaluation of cytotoxic, genotoxic and inflammatory responses of nanoparticles from photocopiers in $3 \mathrm{hu}$ man cell lines. Part Fibre Toxicol. 2013;10:42, https://doi. org/10.1186/1743-8977-10-42.

28. The American Conference of Governmental Industrial Hygienists (ACGIH). Documentation of the threshold limit values and biological exposure indices. 7th ed. Cincinnati: The Conference; 2001.

This work is available in Open Access model and licensed under a Creative Commons Attribution-NonCommercial 3.0 Poland License - http://creativecommons.org/ licenses/by-nc/3.0/pl/deed.en. 